\title{
Comparative Analysis on the Traditional Villages of Folk Groups of Han Nationality in Huizhou
}

\author{
Ying Lai, Xingxing Yang \\ School of Architecture and Civil Engineering, Huizhou University, Huizhou, China \\ Email: lying@hzu.edu.cn
}

How to cite this paper: Lai, Y., \& Yang, X. X. (2021). Comparative Analysis on the Traditional Villages of Folk Groups of Han Nationality in Huizhou. Current Urban Studies, 9, 343-354.

https://doi.org/10.4236/cus.2021.93021

Received: June 11, 2021

Accepted: July 13, 2021

Published: July 16, 2021

Copyright ( 2021 by author(s) and Scientific Research Publishing Inc. This work is licensed under the Creative Commons Attribution International License (CC BY 4.0).

http://creativecommons.org/licenses/by/4.0/

\section{(c) (i) Open Access}

\begin{abstract}
Huizhou, seated in the Pearl River Delta, is located at the intersection of the three main folk groups of Han Nationality of Guangdong. Owing to the different historical sources and the different terrain of the three main folk groups such as Hakka, Guangfu and Chaoshan in Huizhou, village configurations and dwelling morphology differ from each other. Due to the same big Han Nationality and similar climate and landform, they share similar landscape patches, and clan culture in ancestrals. Research work will help the public be aware of the value, which is an efficient way of traditional culture protection and development.
\end{abstract}

\section{Keywords}

Traditional Villages, Village Configurations, Dwelling Morphology, Landscape Patches

\section{Introduction}

Role of traditional villages has been increasingly addressed by the means of protection systems in China. The official protection system of traditional villages has experienced two stages through the latest 20 years (Kuai, 2016): historical famous villages, and traditional villages. The former surveyed the villages which remain rich antiquities with historical value or memorable value. Up to now, 6 groups of China's historical famous villages have been published since 2003, 3 groups of Guangdong's historical famous villages have been published since 2008. The latter surveyed the villages which remain the traditional scenes, or prominent feature of siting and structure, or non-material cultural heritage. Up to now, 6 groups of China's traditional villages have been published since 2012. The civi- 
lian protection patterns of traditional villages are multiple. The strongest civilian protection power is the Federation of Literary and Art Circles and the Folk Cultural Artists Association which has announced 7 groups of Ancient Villages since 2008.

Huizhou, located at the east of the Pearl River Delta, is the only one intersection of the three largest Han multi-folk groups of Guangdong Province. On one hand, by means of the Dongiiang River Huizhou connects Heyuan of Hakka Clan dwellings in the upstream while it connects Canton especially Guangfu Clan dwellings in the downstream. On the other hand, by means of courier route, it connects Meixian of Hakka Clan dwellings in the northeastern while it connects Chaozhou District of Chaoshan Clan dwellings in the east. Besides, in the west it connects Dongguan and Shenzhen, with a majority of Guangfu Clan dwellings and a minority of Hakka Clan dwellings.

As a result, Huizhou has become the only intersection of the three main folk groups, whose villages have formed different treasurable characteristics. Upon the official and civilian protection patterns of traditional villages, many traditional villages outstand, and more than 40 villages have been listed in these catalogs, which covers different folk groups with their strong typicality and representativeness. This paper focuses on the above enlisted catalog comparing the expansion models of traditional villages under the background of Han multi-folk groups in Huizhou.

\section{Individuality Characteristics}

\subsection{Village Configurations}

Cluster of dwellings is the main characteristic of the Hakka villages in Huizhou. Hakka is called China's Gypsy, which means the migrating from one place to another. When they came to Huizhou, most of the easily cultivated delta places had been dwelled by Guangfu Clan, so they had to dwell in the massifs, hills and valleys, not having enough cultivated land. Because they were the late-comers, they had to get united strongly, living in the same roof by the fathers' blood relation, like the original Hakka weilong-house was built. With the increasing of population, when expansion was needed, topography, headwaters as well as clan cohesion had been taken into consideration. The distribution of weilong-house is like dots scattering around not far away from each other giving mutual help. Thereby, the cluster model was in shape (seen Figure 1).

The Yang Family in Liangjing Town Huiyang District is such one sample (Yang, 2015). At the later period of China's Ming Dynasty, Yang Fazun and his family came and built a two rows of five rooms named Shang-Wu-Xia-Wu. At the late Qianlong period of Qing dynasty, his offspring, Uncle Yang Xueqian and the nephew Yang Hongmo co-constructed a large house named Xiangganglou with building area $4100 \mathrm{~m}^{2}$, as time went on, the clan family members became more and more, so the offspring built more houses near Xiangganglou (Seen 


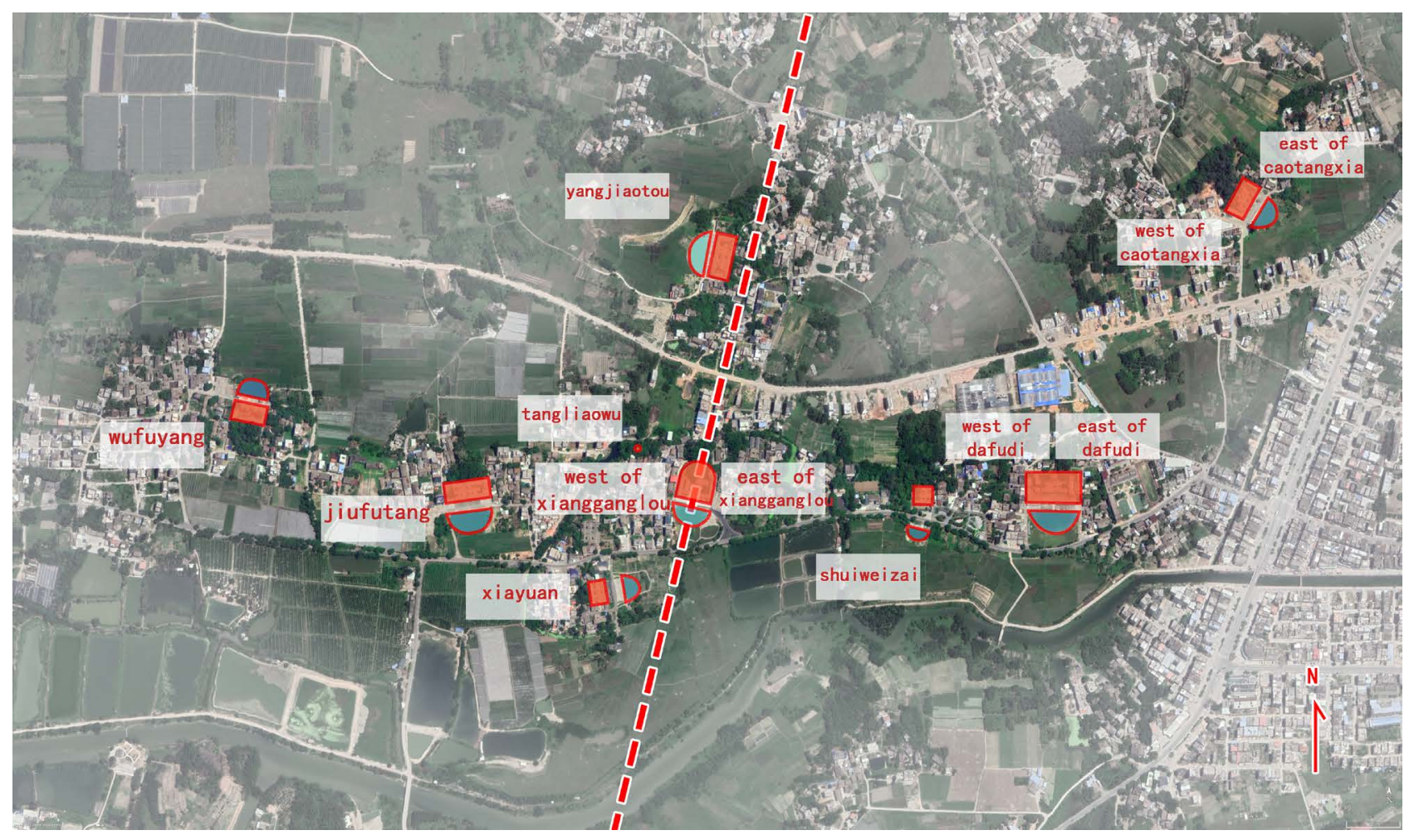

Figure 1. The typical cluster model of Hakka village. The image quoted from Google Map.

Figure 1), such as Zhongxinwu $\left(2770 \mathrm{~m}^{2}\right)$, Wuyangfu $\left(1930 \mathrm{~m}^{2}\right)$, Xiayuan (1200 $\mathrm{m}^{2}$ ), Yangjiaotou $\left(2510 \mathrm{~m}^{2}\right)$, Shuiweizai $\left(1040 \mathrm{~m}^{2}\right)$ and so on. Nowadays, there are more than 20,000 person with the surname of Yang living here.

The comb type layout is a main characteristic of the villages of Guangfu clan in Huizhou. (Seen Figure 2.) The Guangfu villages are basically composed by small dwelling units with the floor area between 90 to 120 square meters, and these small dwelling units stand one by one, row by row. The ancestral halls and other temples stand at the first row of the buildings near the sunning ground, and if there was only one ancestral hall, it would stand at the east or the middle of the village. Although some Guangfu people were very rich, they still wouldn't let all the large clan family members live under the same roof, but divided the clan into small families. The small family is usually composed of father, mother and the children. Sometimes it is composed of the grandfather, grandmother, father, mother and the children. So small dwelling unit is enough for small family. Generally speaking, Guangfu clan are much richer than Hakka because of the fertile land of the Pearl River Delta where Guangfu clan live on. Besides agriculture, commercial crops and trading are also the main means of livelihood. The living pattern of small family can reduce the commercial contradictions and conflicts, meanwhile living regularly in one village may help reduce the commercial risk of dealing with the people outside the village (Guo, 2015).

Density is a main characteristic of the villages of Chaoshan clan. Due to the strongly clan culture, usually the villages are well planned largely, regularly and 


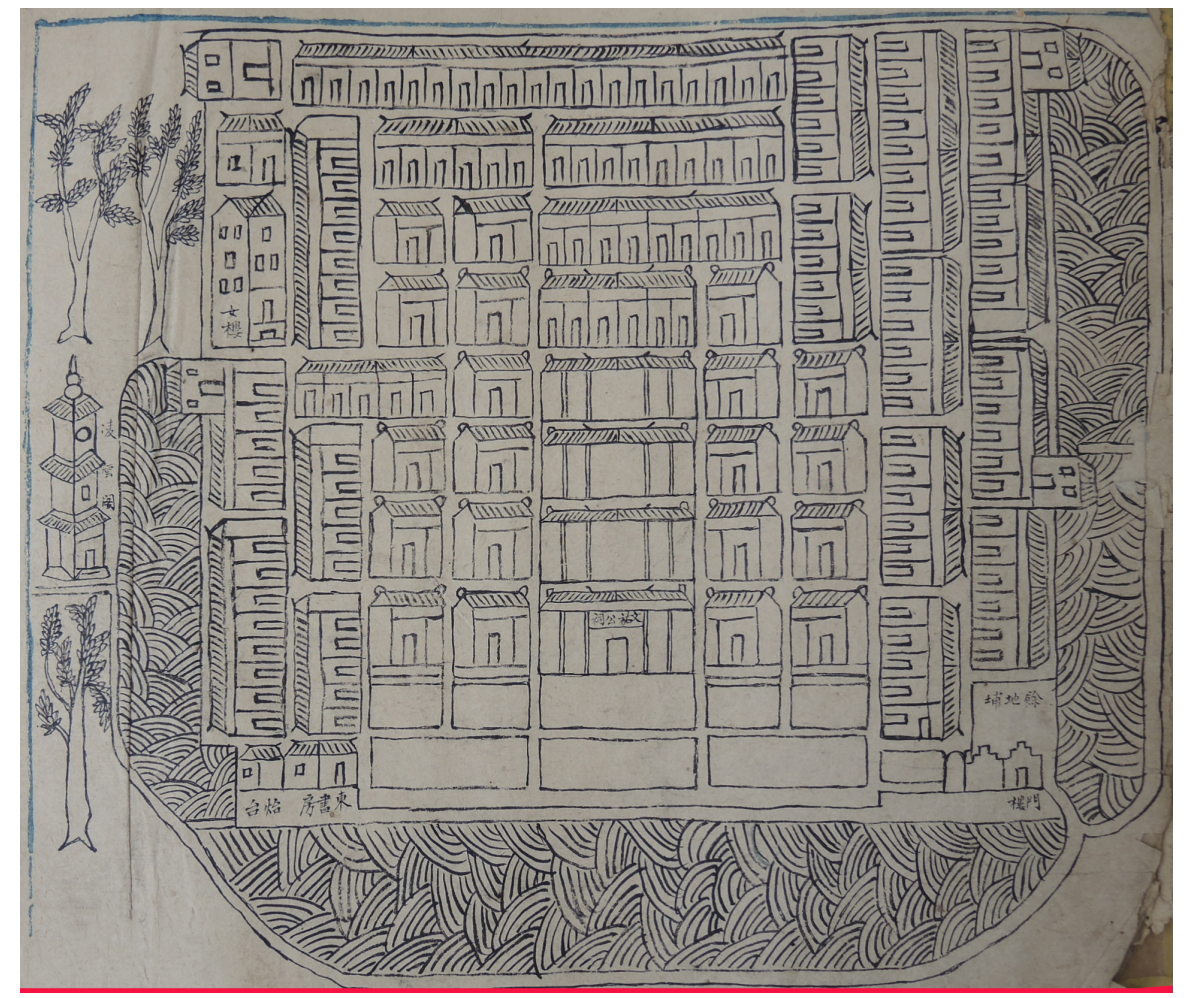

Figure 2. The plan of Wangwu Village, Yonghan Town, Longmen County Quoted from the Family Tree of Wang.

clearly, when there were no more rooms for the increasing family member, some would move out and built some types of small houses such as Pa-Shi or Si-DianJin and so on, some were well planned the others were not. Fanhe Village is such one sample (Seen Figure 3). At the later period of China's Yuan Dynasty, the family of Chan came and built a large enclosing house name Fanluogang Castle in the 8100 square meters area. As time went on, the families of Zhong, Yang, $\mathrm{Zhu}$, and some other surnames came successively and some more dwellings large or small around Fanluogang, some are small houses such as Pa-Shi or Si-Dian-Jin, some are large enclosing houses such as Jitang Castle $\left(3700 \mathrm{~m}^{2}\right)$, Shangde Caslte $\left(3600 \mathrm{~m}^{2}\right)$ Changxing Castle $\left(1500 \mathrm{~m}^{2}\right)$ and so on, Nowadays, there are more than 11,000 person living in this village.

\subsection{Dwelling Morphology}

Dwellings, the main architectures in the village, are different because of the different sub-nation culture, different financial situation and so on. The morphology of villages compared her are most common for the ordinary two-generation family in the three sub-nations.

The Hakka traditional dwellings in Huizhou are expanded at the base of Shang$\mathrm{Wu}$-Xia-Wu (Seen Figure 4) consist of five rooms in width and two rows of buildings, with the center rooms used for entrance hall and ancestral hall and the rest are bedroom. People like to express the scale and structure of the dwelling 


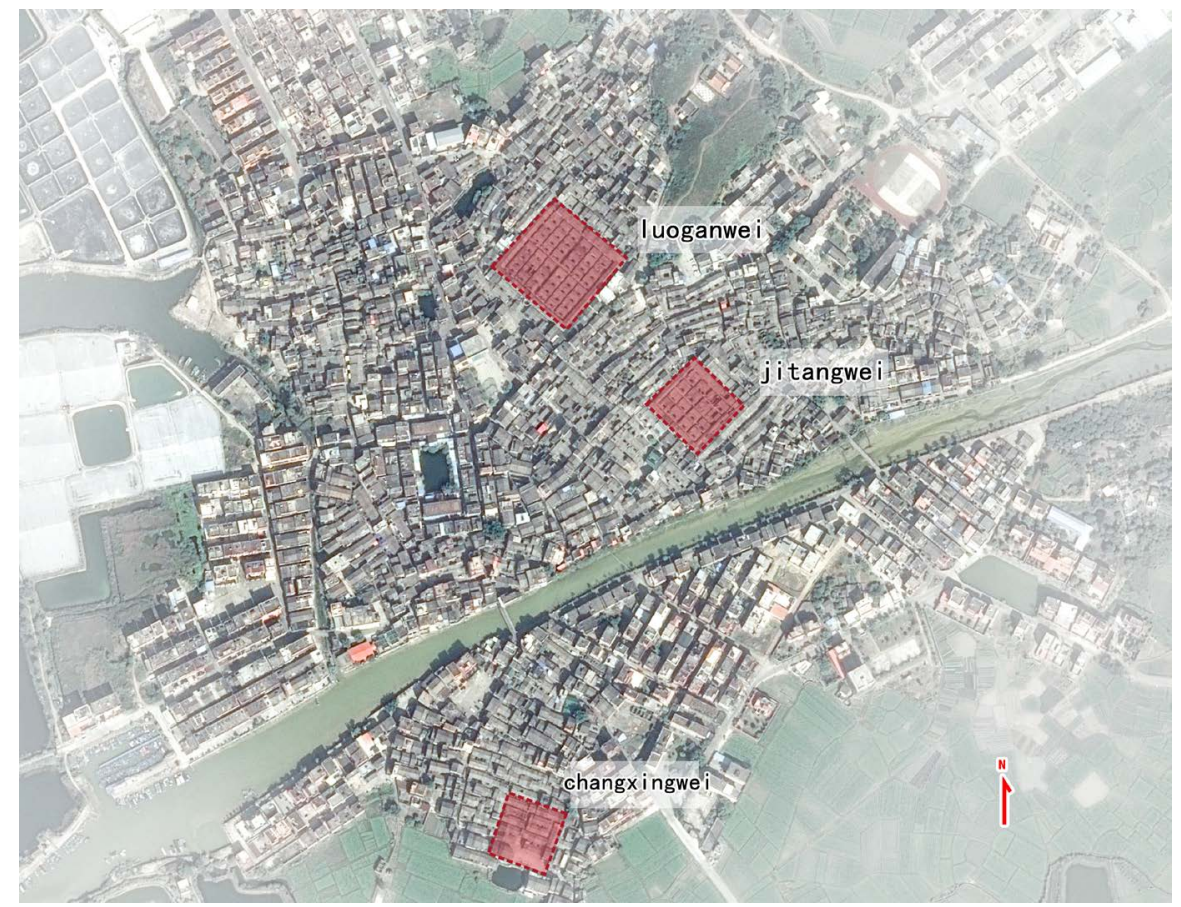

Figure 3. The plan of Fanhe Village The image quoted from Google Map.
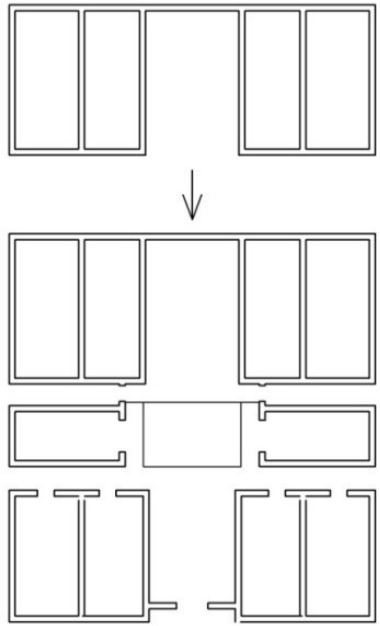

Figure 4. Plan of Shang-Wu-Xia-Wu drawn by the author.

by rooms in width and courtyards, which can be expanded in many ways. Firstly, it can be expanded to seven or even nine rooms with one courtyard between them horizontally, or three or four rows vertically. Secondly, it can be expanded to Liang-Tang-Liang-heng which means two rows of five rooms by adding two columns of rooms on either side of the rows, it also can be expanded to SanTang-Liang-Heng which means three rows of five rooms with two sideways, the three center room of the three rows are used for entrance hall, assembly hall and ancestral hall. This is the most common one in Huizhou Hakka villages. Thirdly, based on the second expansion, it can be expanded to San-Tang-Liang-HengYi-Wei-Long (Seen Figure 5) which means three rows of five rooms with two 
sideways by adding one semi-circle rooms at the rear and the center room used for dragon hall. The Hakka dwellings can be expanded to many many types, some are larger than 10,000 $\mathrm{m}^{2}$, such as Guilin-xinju in Qiuchang Town, Huiyang District, the largest in Huizhou is Chonglin-shiju in Daguang Village (Seen Figure 6), Zhenlong Town, Huiyang District, with the building area 13,800 $\mathrm{m}^{2}$.

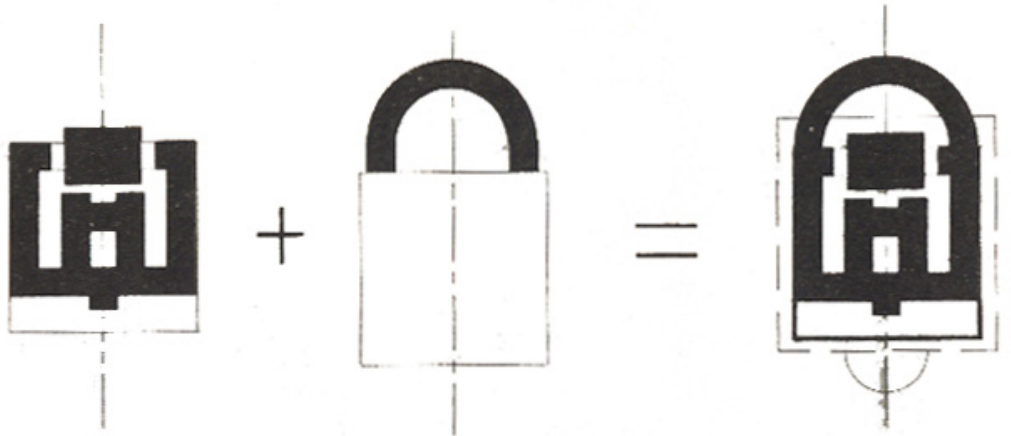

Figure 5. From San-Tang-Liang-Heng to Wei-Long Wu Quoted from Hakka and Hakka Dwellings (Pan, 1998).
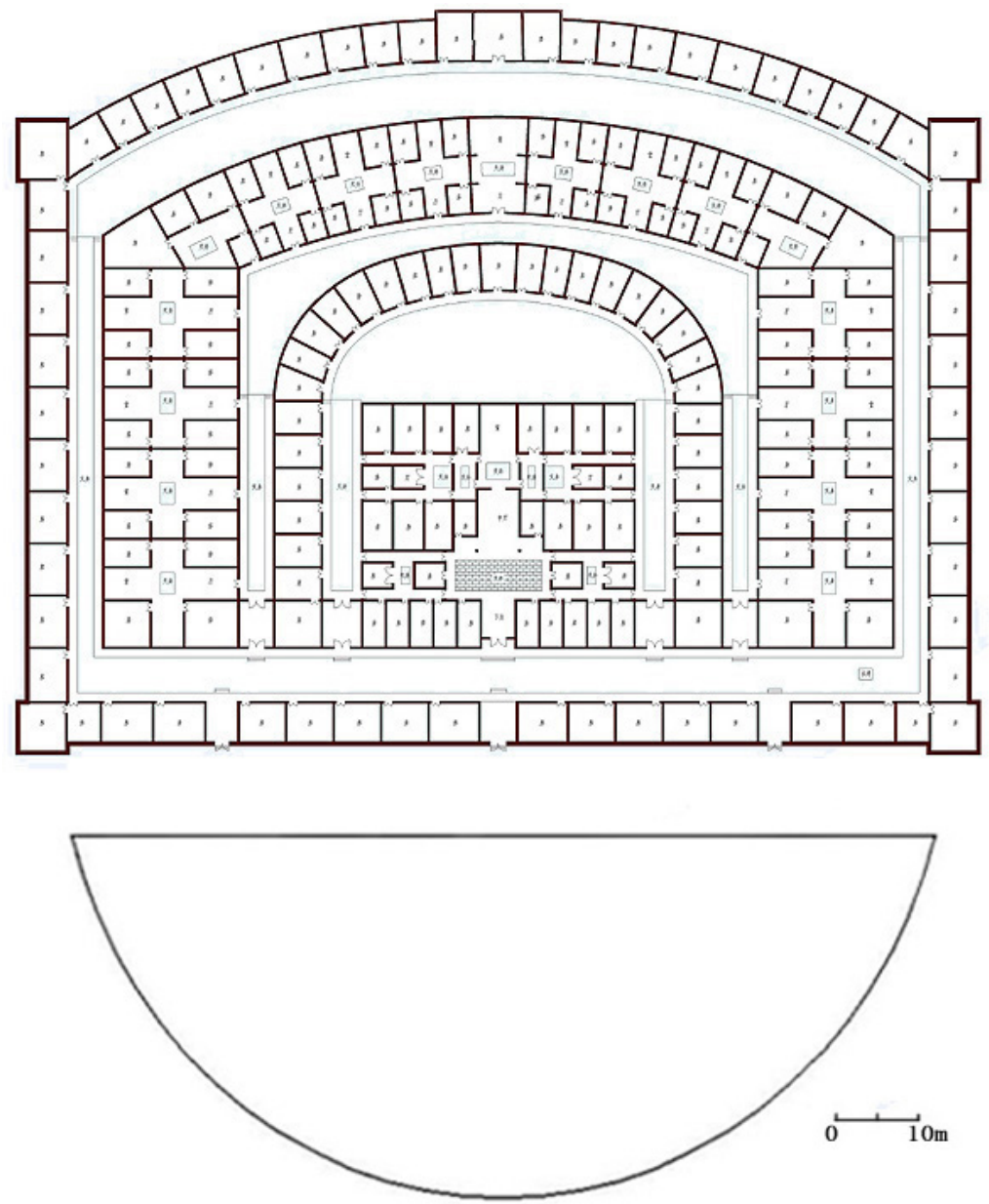

Figure 6. Plan of Guilinxinju quoted from Declaration of Qiuchang Town for National Historical Famous Town. 

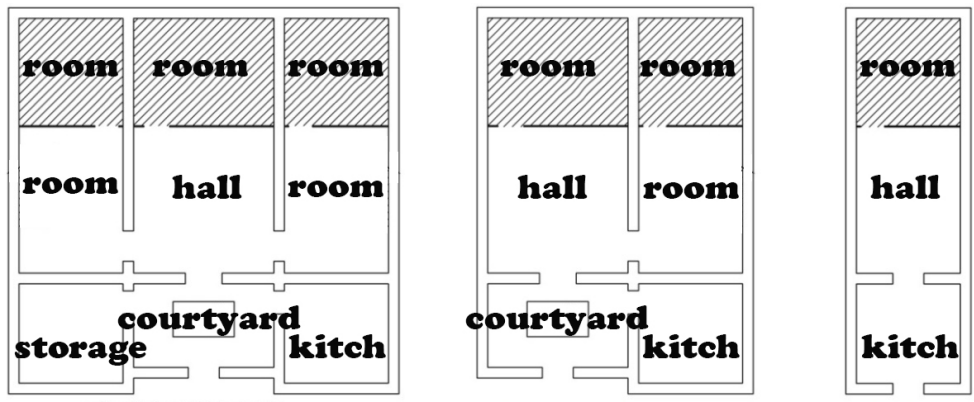

Figure 7. The typical dwellings of Guangfu clan. Drawn by the author.

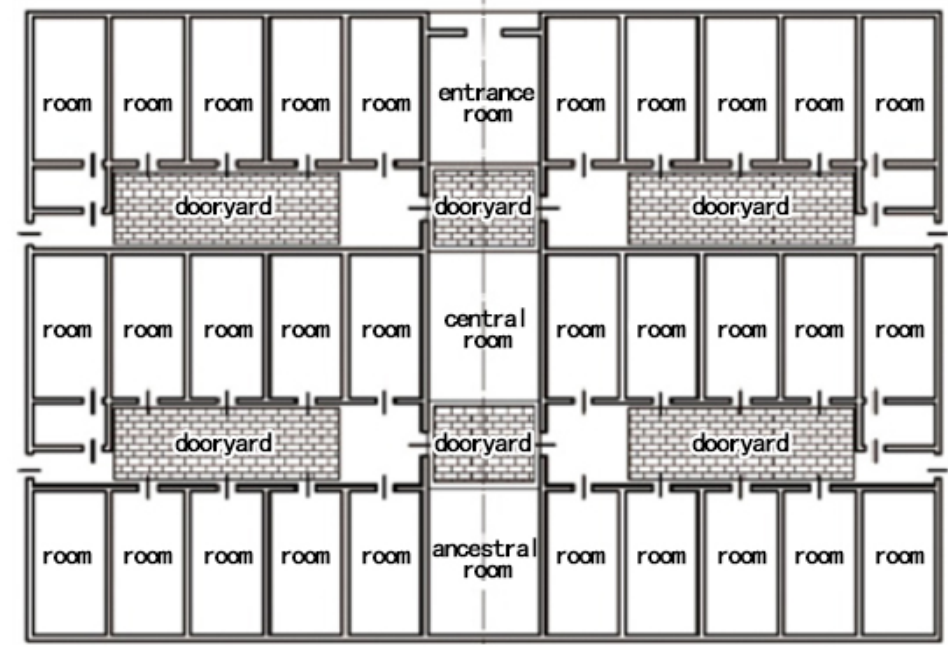

Figure 8. The plan of Former Residence of Millionaire Chan Drawn by the author.

The typical dwellings in Huizhou Guangfu clan traditional villages are SanJian-Liang-Lang (the most widely used), Ming-Zi-Wu, and Da-Qi-Tou (Seen Figure 7). The layout of San-Jian-Liang-Lang is that 3 adjacent rooms at the rear comprised the main part of the house, two small rooms (kitchen and storage) on either side of a central courtyard at the front. This is very common in Guangfu villages in the Pearl River Delta areas. It is used for the family with two or three generations. And the whole Guangfu clan villages is composed of criss-crossing San-Jian-Liang-Langs. The layout of Ming-Zi-Wu with two openings, is smaller than San-Jian-Liang-Lang. Da-Qi-Tou, the smallest, and the most uncomfortable of the three, were usually used along the bounding walls in a large Guangfu village. The three types of small dwellings could be used in one castle. Matugang Village in Yonghan Town Longmen County is such an example. The ancestral hall stands in the middle of the village, and 8 units of San-Jian-Liang-Lang are set at either side of the ancestral hall, two rows of Da-Qi-Tou are along either side of the village bound wall.

There are still some other types of dwelling of Guangfu clan villages in Huizhou. Some family are so rich that even nicely-decorated San-Jian-Liang-Lang couldn't meet their requirements, so they built rows of five or seven of nine 
rooms with at least three halls in the center for public activities(Seen Figure 8), just like the Millionaire Chan in Longhua Town, Boluo County.

The typical small dwelling in Huizhou Chaoshan clan traditional villages is called Pa-Shi (Seen Figure 9), something like San-Jian-Liang-Lang in Guangfu clan, 3 adjacent rooms at the rear comprised the main part of the house, two small rooms (kitchen and storage) on either side of a central courtyard at the front. Some big dwelling is composed of Pa-Shi, such as Luogangwei (Seen Figure 10) in Renshan Town Huidong County. It is square layout with each side length of $90 \mathrm{~m} .7$ vertical lanes and 3 lateral lanes divide the villages into 6 rows of buildings, each row combines 4 units of Pa-Shi. Si-Dian-Jin (Seen Figure 11) is another small dwelling, with the layout is two rows of 3 adjacent rooms with a

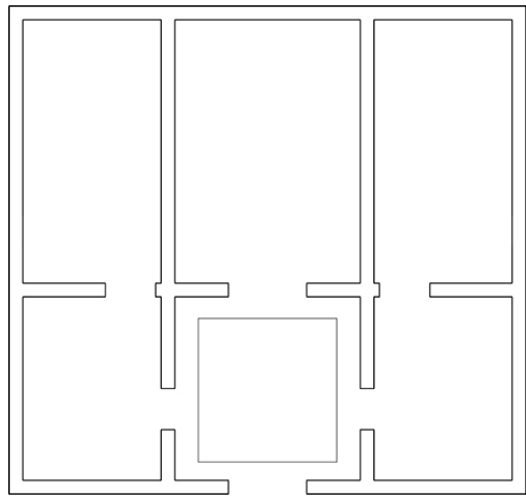

Figure 9. Plan of Pa-Shi drawn by the author.
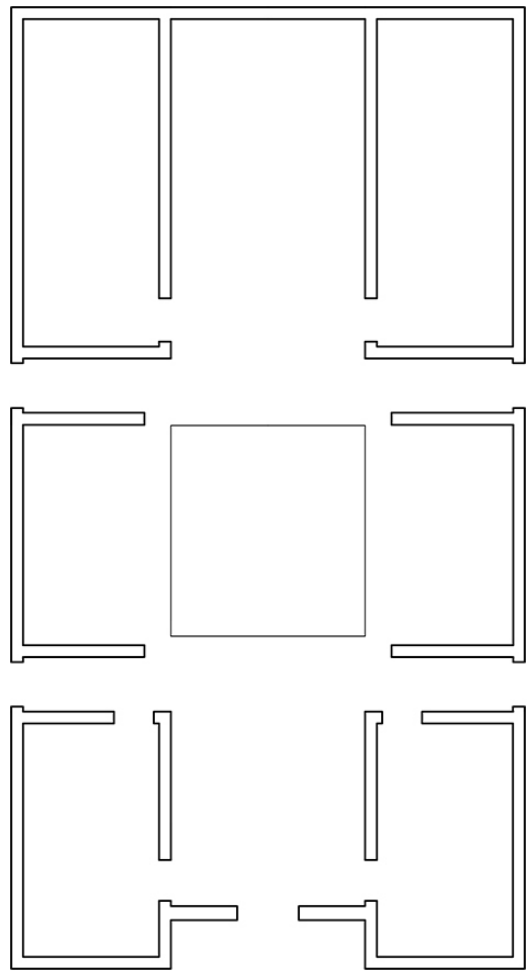

Figure 10. Plan of Si-Dian-Jin drawn by the author. 


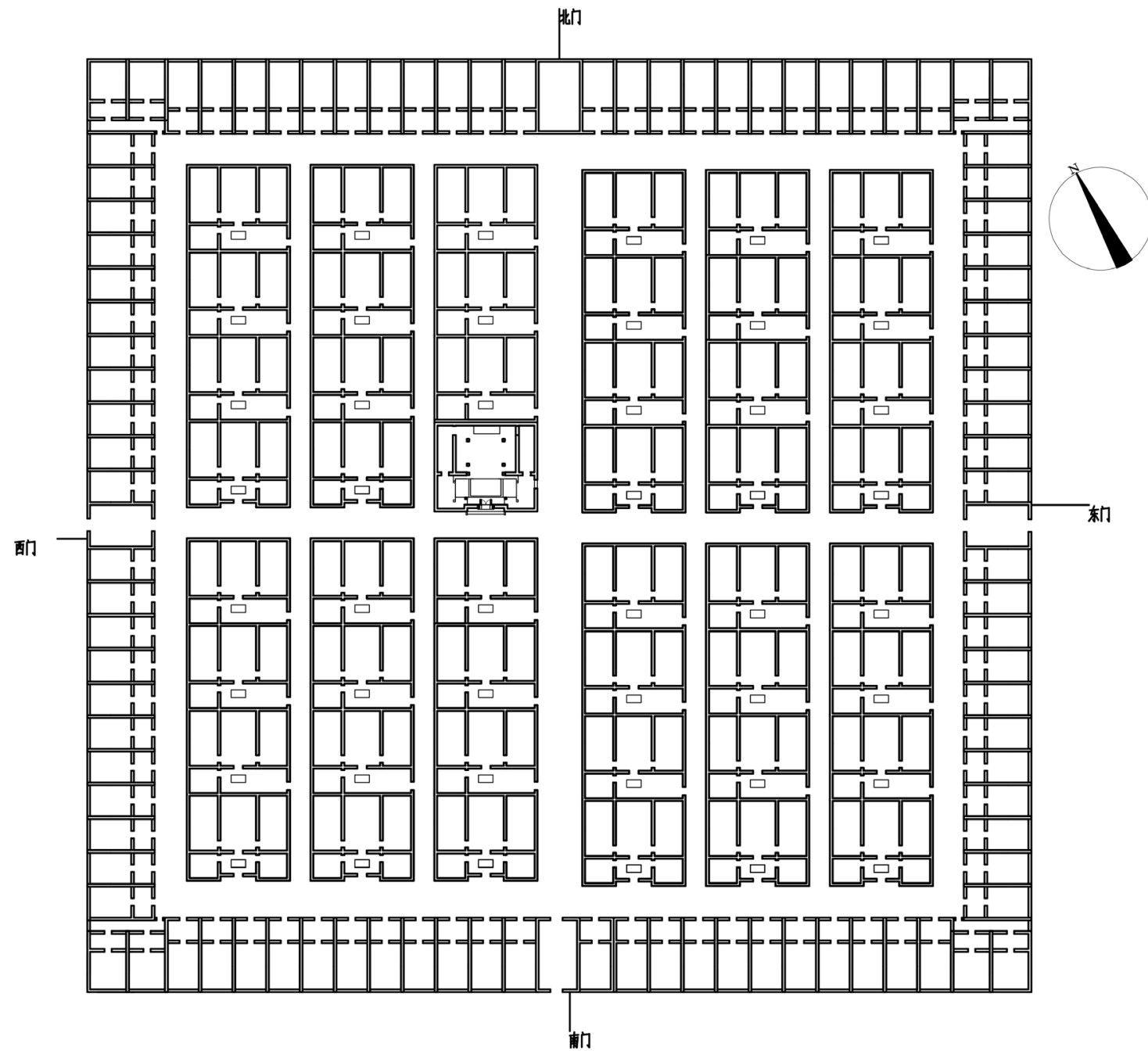

Figure 11. The plan of Luogangwei Drawn by the author.

central courtyard and two small rooms (kitchen and storage) between the rows. It also can be expanded in many ways just like Shang-Wu-Xia-Wu in Hakka. It can be expanded into San-Ting-Chuan by adding 3 adjacent rooms at the rear and two small rooms (kitchen and storage) on either side of a central courtyard at the front. It also can be expanded to $\mathrm{Wu}$-Jian-Guo with layout of two rows of 5 adjacent rooms with a central courtyard and two small rooms (kitchen and storage) on either side of a central courtyard between the rows. It still can be expanded to a large dwelling name Si-Ma-Tuo-Che with the layout of three SanTing-Chuan adding two columns of rooms at the right and left side and one row of rooms at the rear.

\section{Generality Characteristics}

\subsection{Landscape Patches}

Based on the field work and satellite maps from Google, we have found that most villages in Huizhou are composed of five following similar landscape patches 
(Seen Figure 12). Firstly, the back hill full of varieties of trees. The back hill, the highest elevation of the village, are mostly natural or part-natural formation which is a main positive factor of village siting. But if the village landscape is so flat that the back part has to be lifted manually. Secondly, the crisscrossing buildings for dwelling. The buildings can be divided to residential buildings and public buildings, such as ancestral hall, temples, gate houses, blockhouses, etc. Thirdly, the sunning ground between the buildings and the pond. The sunning ground is used for drying grain, gathering, performing lion dance and so on. Fourthly, pond. Pond is very important for a village, for it undertakes lots of functionalities such as water retaining, fish farming, irrigating, washing etc. The fifth, the cultivated land. The cultivated land is the main means of getting food. It's near the pond just because of convenient irrigation.

In accordance with the terrain and topography, the five patches have been designed with the front lower than the rear. The sloping is determined by the needs of drainage. Huizhou is a flat watery land, most villages are under 100 meters above sea level, some are only several meters above sea level, although inhabiting by water is the natural selection, but it is more important for villagers dwelling here to drain. The slope makes the rainfall vanish quickly, the pond lower can retain the rainfall.

An overwhelming majority of the villages' siting is depended on the peripheral environment and the terrain topography, so the orientation of villages is much different. Generally speaking, towards the southeast or south is the best choice of village cite selection, and also is the common choice, because the woods on the north hill can stop the cold winds from the north in winter, while the open plain on the south or southeast can lead in the cool winds from the southeast in summer. However, due to the river direction, which is the main the orientation of village may have to adjust, compared to the first choice of south or southeast choice, facing east is a second choice, symbolizing the violet hazes coming from the east. But sometimes, if the river comes on the north or the west, or some

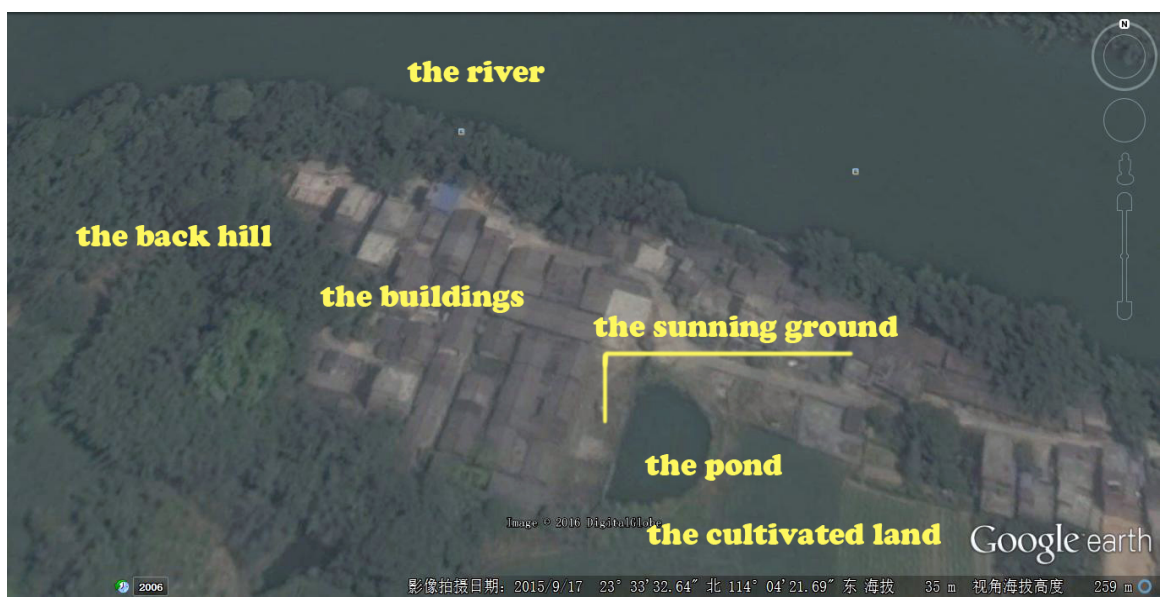

Figure 12. The early well-planned regular large dwelling The image quoted from Google map. 
other reasons, the orientation of village has to face north or west. Like Shengwu Village in Longmen County facing north, the reason is that Zeng River runs from east to west, and turns the direction from north to south at the northwest of Shengwu Village. Like Huangwu Village in Zhongkai District facing west.

\subsection{Clan Culture in Ancestral Halls}

Ancestral halls are the most significant, nice crafted in each village in Huizhou. There is at least one ancestral hall in one village, sometimes a dozen or dozens of ancestral hall in one village. Take Huzhenwei Village as an example. Hu clan family came to Huzhenwei Village at the late of South Song Dynasty, and began to build ancestral hall in Ming Dynasty, as time went on, more and more ancestral halls had been built. Till now, 8 ancestral halls have been left: the Hu Clan Ancestral Hall, Yukuan Ancestral Hall, Ximeng Ancestral Hall, Dongling Ancestral Hall, Deji Ancestral Hall, Dezhong Ancestral Hall, Xunzhong Ancestral Hall, Chuntang Ancestral Hall. The first hall is for worshiping the ancestors of all the big $\mathrm{Hu}$ clan family, the later seven halls are for worshiping the ancestors of the branches of big Hu clan family. The ancestral halls have been undertaking worshiping the ancestors, meeting and other public events.

The activity of shangdeng is the most solemn of all the folk ceremonies in Huizhou. Shangdeng (Seen Figure 13) is a ceremony of cerebrating the newborn boys of the last lunar year during the first fifteen days of the first lunar month. There are many steps to carry on the activity, the most solemn step is to hang over the lanterns (the same pronunciation as deng) on the pillar of the ancestor room in the hall. Some villages take much time and spirit on it. It takes nearly twenty steps and one and half a months to hold the whole ceremony in Huzhen Village, Huzhen Town, Boluo County.

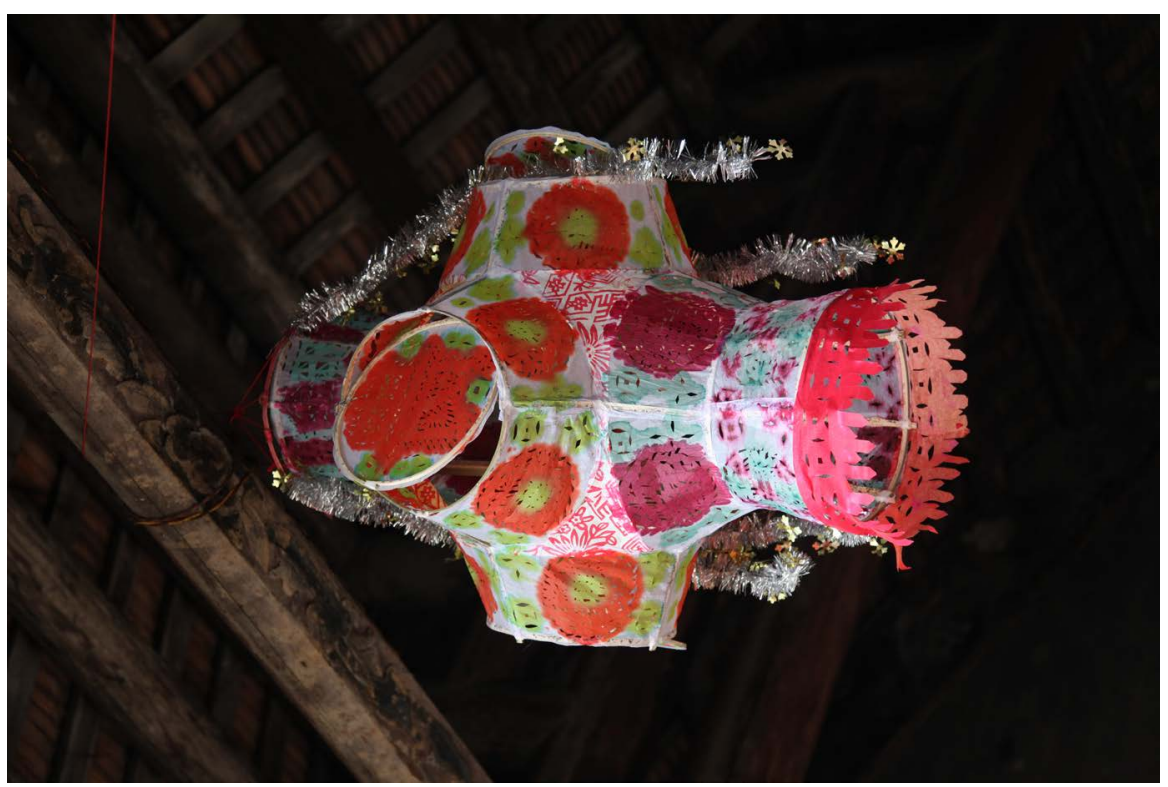

Figure 13. Lantern in Ancestral Hall of Huzhen Village. 


\section{Conclusion}

Huizhou is the only city that boosts of three multi-folk groups in Guangdong province. Due to the different cultures of Hakka, Guangfu and Chaoshan, thus their village configurations and dwelling morphology differ from each other. Due to the same nationality and similar landform, they share similar landscape patches, and clan culture in ancestrals. The study on traditional village not only just echoes to the hot issues these days, but also responds to the requirements by the State Council that Huizhou as a National Famous Historical and Cultural City should study and explore the connotation and value of historical and cultural heritage. Besides, it helps to arouse people's understanding to the values of traditional villages and build a solid foundation for rural revitalization scheme tourism culture exploration.

\section{Conflicts of Interest}

The authors declare no conflicts of interest regarding the publication of this paper.

\section{References}

Guo, H. Y. (2015). A Comparative Study on the Vernacular Architectural Culture of Guangdong Overseas Chinese Hometown of Modern Times. Thesis, Guangzhou: South China University of Technology, 31.

Kuai, Y. L. (2016). Research on Traditional Villages' Protection System in China. Modern Urban Research, 1, 3.

Pan, A. (1998). Hakka and Hakka Dwellings. Beijing: China Architecture \& Building Press, 68.

Yang, X. X. (2015). Hakka Enclosed Houses in Guishan County of Qing Dynasty. Beijing: The People's Daily Press, 41. 